\title{
Explicitation in Translation: A Case of Screen Translation
}

\author{
Masumeh Yazdani Moghaddam \\ English Department, Zabol University, Sistan and Baluchistan Province, Iran \\ Sommayeh Shahraki Deh Sukhteh \\ Zabol University, Iran \\ Mansureh Delarami Far \\ English Department, Sistan and Baluchistan University, Iran
}

\begin{abstract}
Explicitation is a method of clarifying into the TT what is implicit in the ST. Blum-Kluka (1986) formulated explicitation hypothesis and regarded explicitation as a translation universal, i.e. a feature that is mainly existed in the translated texts. So, the present study considers expliciation in screen/film translation, and tries to investigate the most frequent explicitation type and subtitling strategies used by the Persian subtitlers. To achieve the goals of the study, the three original English films subtitled into Persian language were selected and the first 20 minutes of them was studied and compared with their Persian equivalents through sentence-by-sentence comparison. The subtitling strategies were identified and their percentage was calculated. The findings indicated that translation-inherent explicitation was used mostly in subtitling, and expansion was the most frequent subtitling strategy employed by the Persian subtitlers in subtitling English original films into Persian.
\end{abstract}

Index Terms - audiovisual translation, English language, explicitation, Persian language, strategies, subtitling

\section{INTRODUCTION}

Translation is a way of transferring ideas and facilitating communication among nations and translators should be qualified in a wide range of issues especially Source Language (SL), Target Language (TL) and content of translation as one element. Hence, as Gouadec (2007) mentions "languages are essential, but insufficient; what is needed beyond absolute linguistic proficiency is a perfect knowledge of the relevant cultural, technical, legal, commercial backgrounds and full understanding of the subject matter involved." (p. xii) He further argues that translation allows effective communication; and "it is vital for the dissemination of goods, products, services, concepts, ideas, values, etc.." (p. 5) Reiss and Vermeer (Cited in Hatim and Munday, 2004) also assert that translation of a text should perform the concerned purposes of it in the TL and culture. Gouadec (2007) states that translators must comply with the following issues: (a) the client's aims and objectives; (b) requirements of the users; (c) the standards and conventions, value systems, modes of reasoning, terminology, etc. of the related community, so the translation must represent the community of the people speaking that specific language. He also enumerates the features of quality translation: (a) accuracy which means the contents should be conveyed truly; (b) meaningfulness: the message must be meaningful in the TL and culture; (c) accessibility: readerships of the translation should be able to understand the information and message conveyed through translation; and (d) effectiveness: translation must fulfill the purposes of its users.

When translating from one language into another, different issues should be considered by translators such as semantic, syntactic, etc. Preserving natural and clear meaning of the ST in translation needs understanding original text, its purpose and readership in the TL. Therefore, in those cases which TT is not clear for readerships, translators add some elements to clarify meaning, i.e. they turn to explicitation. Séguinot (1988) argues that explicitaion should be considered as additions which cannot be expressed by structural, and stylistic differences between the SL and TL and further reiterates that addition is only one way of showing explicitaion; other ways are the cases where: (a) implied information are overtly expressed in translation; (b) the elements of SL text are given emphasis in translation by various methods such as focus, emphasis and lexical choice. This research is a focus on explicitation in subtitling original English films into Persian language.

\section{StATEMENT OF The Problem}

Subtitling is a form on AVT which is increasing in screen translation all over the world. Therefore, when subtitling in the act of translation from one language into another, subtitlers face different issues such as how to subtitle verbalvisual signs, kinetic elements, silences in the film, etc.. The subtitlers should identify such elements in the film and render them in the written form of TL as accurately and naturally as possible. Hence, spoken forms are different from 
written ones and subtitlers should take these issues into account. In general, they should subtitle films and their audiovisual elements in such a way that be comprehensible to the TLs' viewers. To achieve this goal, loss and gain are necessary in the process of translation when subtitling. Thus, one of these strategies is explicitation which helps subtitlers to make film more understandable to the audiences, and it is of an absolute necessity for natural and accurate subtitling when films and audio-visual products are translated.

\section{SignificAnCE AND PURPoSe OF THE StUdy}

Subtitling and its strategies in translation is one aspect of AVT and the subtitlers should have careful attention to the aim, audiences, and TL norms. The study helps researchers in the field of translation especially AVT. It is also to the benefit of the translators, film/screen translators, and is a helpful source for the translation students. It can also open a new avenue for subtitlers. The purpose of the study was to identify subtitling strategies in translation and expliciation type into account in AVT genre.

\section{RESEARCH QuESTIONS}

1. Is there any explicitation in subtitling film from English into Persian, and if yes, what is the most common explicitation type?

2. What is the most frequent subtitling strategy from English into Persian in AVT?

\section{REVIEW OF THE RELATED LITERATURE}

Explicitation and implicications are issues which exist mostly in spoken and written. Becher (2011) defines implicitness as "the non-verbalization of information that the addressee might be able to infer." (p. 18) From his point of view, explicitness refers to verbalization of information that can be understood if not stated clearly. The focus of attention in this study is on explicitation, so implicitation needs a separate research.

Blum-Kluka (1986) introduces the term expliciation hypothesis in translation studies and argues that in rendering and interpreting SL into the TL text, translators might produce a TL text which is more redundant than the SL text. Séguinot (1988) further states that "explicitation should therefore be reserved in translation studies for additions in a translated text which cannot be explained by structural, stylistic, or rhetorical differences between the two languages." (p. 108) He phrases that expliciataion has three forms in translation: (a) an element or item which is not in the ST but experienced in translation; (b) an item which is implied in the ST is explicitated in the TT; and (c) an item in the ST is getting more attention and importance in translation by emphasizing and lexical choice.

Baker (1993) argues that universals of translation are features which are common in translated texts rather than original ones; and states that they are identified by contrastive analysis of Source Text (ST) and their translations. She identifies some of these features as follows: (a) simplification; (b) avoidance of repetitions existing in the SL; (c) explicitation; (d) distinctive distribution of lexical items; (e) discourse transfer; and (f) normalization. Pym (2005) also expresses that "expliciation takes place, for example when a SL unit of a more general meaning is replaced by a TL unit of a more special meaning; the complex meaning of a SL word is distributed over several words in the TL." (p.4)

One aspect of Audiovisual translation (AVT) is screen translation which has different varieties such as subtitling, dubbing, etc.. This study considers one form of screen translation i.e. subtitling. It is identified as a special type of translation. (Hatim \& Mason, 1997). Gottlieb (1998) enumerates two forms of subtitling namely intralingual and interlingual subtitling; by intralingual he means subtitling within SL itself, and interlingual subtitling refers to subtitling in the TL. These two kinds of subtitling are used as a way of teaching and learning foreign languages. (Diaz Cintas, 2009; Gambier, 2003). Gottlieb (1998) also maintains that "subtitles usually consist of one or two lines of an average maximum length of 35 characters, and they are placed at the bottom of the page in general." (p.245) From his perspective, semiotic composition, time and duration, and pragmatic dimension are distinctive features of subtitling. Under semiotic composition he argues that translators have four channels for communication in film and screen programs: (a) "the verbal auditory channel; including dialogue, background voices, and sometimes lyrics; (b) the nonverbal auditory channel including music, natural sound, and sound effects; (c) the verbal -visual channel including written signs on the screen, and (d) non-verbal-visual channels are picture composition." (p. 245) By time and duration he mentions time for text production and its presentation in the TL; and pragmatic aspect should consider audience understanding of the film. The study aimed at investigating explicitaion in AVT. Klaudy (1998) defines explicitaion as a technique which produces and makes clear that information in the Target Text (TT) that is implicit in the Source Text (ST) and asserts that explicitation is inherent in the act of translation. Klaudy (1998) introduces different types for explicitaion: (a) obligatory explicitaion which consider semantic and syntactic differences between the two languages, so this type is obligatory since without applying them in translation, TL sentences are not correct grammatically; (b) optional explicitaion relating to stylistic difference and text building strategies between the two languages; they are optional because neglecting them lead to unnatural texts while the texts are grammatically correct; (c) pragmatic explicitaion considers cultural difference among languages; i.e. in cases where there are cultural difference between the two language such as food items, geographical names, etc., the translator uses expliciation to avoid ambiguity and (d) translation- inherent explicitaion related to the nature of the translation process itself. 


\section{Audiovisual Translation}

Diaz Cintas (2009) states that there are two basic approaches in transferring the original speech into another language" either oral output remains oral output, as in the original production, or it is transformed into written output; if the first option is adopted, the original soundtrack is replaced by a new one in the TL, a process which is generally known as revoicing". (p.4) AVT has a wide variety, film translation is one part of AVT; TV series, documentaries, videogames, etc. constitute other aspects of AVT (Diaz Cintas, 2009). AVT is ever increasing in the globe especially in the area of screen translation. In AV genre, the translators render the spirit of the work to their audience rather than providing a literal translation of spoken words (pettit, 2004).

In language transfer on the screen, the replacement of material from one language into another may be total, as in the cases of lip sync dubbing and narration where we do not hear the original soundtrack; or partial, as in voiceover and interpreting where the original soundtrack can be heard in the background (Diaz Cintas and Anderman, 2009).

Bartrina (2004) states that synchrony between verbal and non-verbal messages are of paramount importance and necessity to understanding the intended meanings in AVT. Diaz Cintas (2009) also states that "AVT is the means through which not only information but also the assumptions and values of the society are filtered and transferred to other cultures". (p. 8) He further argues that in AVT, translators should have close attention to the audiovisual context, to the established relationships between images, character interaction and individual verbal strategies, i.e. they should consider semiotic aspects of AVT.

\section{SUBTITLING AND DUBBING}

Based on Diaz Cintas (2009) subtitling, dubbing, and voice over are three modes of AVT. According to him "subtitling involves presenting a written text, usually along with the bottom of the screen, which gives an account of the original dialogue exchanges of the speakers as well as other linguistic elements which form part of the visual image (insert, letters, graffiti, banners and the like) or of the soundtrack(songs, voices off)." (p.5) According to Pettit (2004) "in a subtitled version the viewer hears the dialogue in another language, reads the subtitle and watches the picture; in a dubbed version, the viewer listens to a translated version of the original dialogues while watching the original image." (p.31)

Georgakopoulou (2009) argues that "subtitles need to comply with certain levels of readability and be as concise as necessary in order not to distract the viewer's attention from the programme." (p.21) From his point of view, the shift from speech to writing form is a challenging issue for subtitlers; for instance, pauses, false starts, unfinished sentences, ungrammatical constructions, slips of the tongue, dialectal, idioletcal and other pronunciation features are difficult to render in subtitling in writing form. Considering subtitling strategies, Georgakopoulou (2009) highlights that reductions is obviously the most important strategy in subtitling, and the expansion rate is $30 \%$ to $40 \%$ when translating from English into most European languages. As for subtitling, Pettit (2004) mentions that in AV genre especially in news programme and documentary "the subtitler prefers to remain very close to the original dialogue ensuring that the audience will receive the essential facts with the esthetic concerns being of lesser importance." (p. 37) Sanchez (2004) maintains that subtitling methods and procedures depend upon client and studio.

Dubbing also refers to the replacement of the original soundtrack with that of the TL so that TL sounds and the actors' lip movement synchronized, and the TL viewers believe the actor on the screen are speaking their language. (Diaz Cintas, 2009) Voice over also represents "reducing the volume of the original soundtrack to a minimal auditory level, to ensure that the translation, which is orally overlapped onto the original soundtrack, can be heard by the target audience." (Diaz Cintas, 2009, p. 5) He argues that in this mode of AVT the recoding of translation finishes seconds before the end of the original speech, therefore, provide the audience with the chance to listen to the original speech on the screen. From his point of view, dubbing, subtitling, and voiceover are translational modes which belong to audiovisual text type as opposed to written and spoken text types. Baker and Hochel (1998) also introduce subtitling and dubbing as the most well-known modes of AVT. But Bassnet (2002) puts subtitling and dubbing on the category of literary translation. Zoepettit (cited in Diaz Cintas, 2009) phrases that nonverbal elements of films are often neglected in translation when subtitling since they cannot be produced in written text into the TL. Perego (2003) also emphasizes that neglecting nonverbal elements in subtitling affect understanding and comprehension of the message since nonverbal dimensions transfer the information for the SL to TL and also complete the verbal message and support those strategies which attach great importance to the silences, kinesics, proxemics, and other paralinguistic features in translation when subtitling. As for subtitling and dubbing, Sanchez (2004) argues that subtitled and dubbed dialogue do not synchronized; and time discrepancy is one issue which leads to differences in subtitled version and dubbed one of a film.

Considering subtitling strategies, Gottlieb (1994) enumerates the following strategies: (a) transferring; (b) expansion; (c) condensation; (d) paraphrase; (e) imitation; (f) transcription; (g) omission; (h) resignation; (i) decimation and (j) dislocation. Regarding these strategies, he mentions that omission strategy, transcription, dislocation, and condensation are used with highest frequency in subtitling. Sanchez (2004) also identifies four subtitling methods namely pretranslation, spotting, adaptation and translation. Jabbarzadeh (2007) studied ten Iranian and American subtitled film with focusing on translational norms. She found that in these subtitled films, the informal forms were replaced by 
formal ones; the culture specific items: (a) were replaced by proper target culture specific items; (b) were omitted; (c) were preserved and also were translated to be understandable. Jabbarzadeh further came up with the result that verbal visual signs were not subtitled, songs were either subtitled or not subtitled; and social dialects were also preserved. Roozgar (2007) studied textual expliciation in expressive and informative text types. In his study the data were extracted of the first 200 translated sentences of the three informative and expressive text types. The STs were analyzed to identify explicitation cases. The study came to the conclusion that firstly, informative texts are explicit by nature and are more explicit than expressive ones; secondly, explicitation is much higher in the translation of informative texts than expressive ones.

\section{METHOD}

This study was a descriptive one in nature, and the purpose was to consider explicitation in subtitling film from English into Persian and also to identify the most frequent type of subtitling strategies used by the subtitlers in subtitling English films into Persian language. To achieve the goal of the study, three original English films subtitled into Persian were chosen and the first 20 minutes of them were examined. Then, the cases of explicitation and subtitling strategies were identified. Finally, attempt was made to analyzed the data based Klaudy (1993)'s explicitation types and Gottlieb (1994)'s subtitling strategies. The following English films subtitled into Persian constituted the material of the research:

1. Lost: it is a drama series with science fiction elements, and aired from 2004 to 2010 in American TV. It is about a plane crash and its survivors who lived with each other on a remote island; critics argue that it is one of the top 10 series in the history of American television and won numerous awards including Golden Globe Award for drama in 2006.

2. Princess Protection Program: it is about a princess whose country was invaded and forced to go to America where nobody knows of her until the situation in her country become safe for her to return. It released in 2009 in U.S. in English language and won the Teen Choice Award in 2009.

3. The Lake House: it is a romantic drama film, released in 2006 in English language in the U.S.; the film focuses on an architect and a doctor living in two different times and met with each other by letters left in a mailbox, and they were separated from each other by this time difference.

\section{Data Collection Procedures}

The study aimed at identifying subtitling strategies in AVT. To achieve the objective of the study, the first 20 minutes of the intended English films were considered. Then, attempt was made to identify the most frequent subtitling strategy and explicitation applied in these subtitled films. The first 20 minutes of English films were compared with their Persian subtitled through sentence by sentence analysis to identify strategies and types of explicitation used by Persian subtitlers. Finally, the data were analyzed and their percentage was calculated.

\section{Results AND Discussion}

To fulfill the goal of the study, and provide answer to questions, some examples were included and also descriptive findings of the data were presented as follows in tables and figures:

Examples extracted from the corpus:

- All clear? Clear $\rightarrow$ همد كنار؟ كنار

- There you go. Mm..hm. Stop (eating), now (eat) بفرما، ممم، وايسا، حار كالا

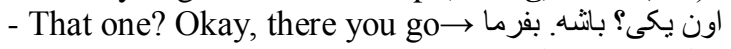

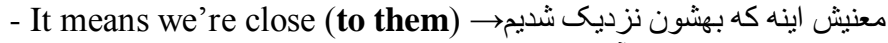

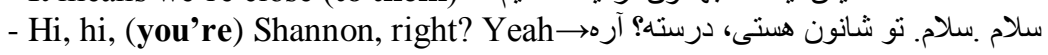

- Hypothetically, yes (I can find it). فرض كن مى نونم آرمن $\rightarrow$

In the first three examples Persian subtitlers used transferring strategy, and in the second three ones, they employed expansion strategy.

-You are...(protecting your mother) $\rightarrow$ i condensation strategy

- Sure, there is. $\rightarrow$ omission strategy

- Thanks for coming to help Rosolinda $\rightarrow$ omission strategy

TABLE 1.

FREQUENCY OF SUBTITLING STRATEGIES FROM ENGLISH INTO PERSIAN IN THE CORPUS

\begin{tabular}{|l|l|}
\hline Strategies & Frequencies \\
\hline Transferring & 96 \\
\hline Expansion & 54 \\
\hline Omission & 27 \\
\hline Condensation & 6 \\
\hline
\end{tabular}




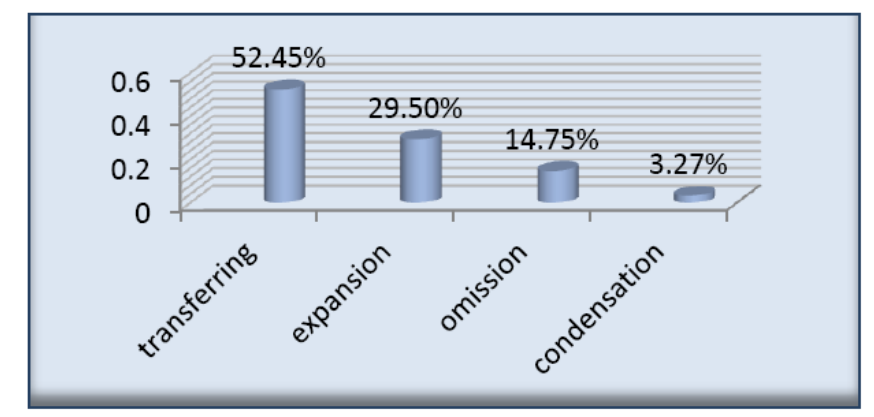

Figure 1. Percentage of subtitling strategies from English into Persian in the Corpus

As table 1 and figure 1 indicate transferring has the highest frequency (96) and percentage (52.45\%) in the corpus and condensation contains the lowest percentage $(3.27 \%)$.

The study attempted to identify the most frequent subtitling strategy in subtitling English original films into Persian language and also to determine the most common explicitation type in subtitling English films into Persian. Based on descriptive data, the study indicated that transferring strategy was applied with the highest frequency (96) in comparison with the other subtitling strategies in the corpus and condensation had the lowest one (6). Thus, considering the first research question and providing clear answer to it, the study found that there were explicitations applied in subtitling films from English into Persian and the translation-inherent expliciation was used in most cases by the subtitlers; since subtitlers conveyed the information that was conceived in the SL. As for the second research question, it was crystal clear in the data section that transferring strategy was used with the highest frequency by the Persian subtitlers in subtitling English films into Persian. These may be because of the following reasons: (a) speakers in film are in direct and face-to-face contact with each other, so there is no need for explicitation because some semantic aspects and implied meanings are conveyed through facial expression; thus, subtitling related to written language and subtitlers might need to explicit those implicit meanings; (b) subtitlers may want to render information explicitly to perform communicative translation.

\section{CONCLusions}

Expliciation is a process of clarifying meaning in the TL which requires translators to make some additions in the act of translating from SL into TL. It has different types and translators apply them based on purpose of translation and target readerships. Expliciation in subtiling films is also employed differently depending on subtitlers native language structure and subtitling strategies. As it was stated before, the research aimed to consider the most frequent subtitling strategy applied in English films subtitled into Persian language; and also to investigate the type of explicitation used in subtitling these three films. The study concluded that transferring was employed with the highest percentage (52.45\%) in subtitling and condensation was rendered with the lowest percentage (3.27\%); and translation-inherent explicitation was used in most cases by the Persian subtitlers.

\section{REFERENCES}

[1] Baker, M. (1993). Corpus Linguistics and Translation Studies: implications and Applications. In: M. Baker, G. Francis and E. Tognini-Bonelli (Eds.), Text and technology: In honour of John Sinclair. pp. 233-250. Amsterdam and Philadelphia: John Benjamins.

[2] Baker, M. \& Hochel, B. (1998). Dubbing. In M. Baker(Ed.). Routledge encyclopedia of translation studies. pp. 74-76. London and New York: Routledge.

[3] Bassnett, S. (2002). Translation Studies ( $3^{\text {rd }}$ ed.). London and New York: Routledge

[4] Bartrina, F. (2004). The Challenge of Research in Aduiovisual Translation. In P. Orero (Ed.). Topics in Audiovisual Translation (2004). Pp. 120-127. Amsterdam: John Benjamins.

[5] Becher, V. (2011). Explicitation and implicitation in Translation:A corpus-based study of English-German and German-English translations of business texts. PHD Dissertation. Hamburge University.

[6] Blum-Kulka, Sh. (1986). Shifts of cohesion and coherence in translation. In L. Venuti (Ed.). The Translation Studies Reader. (2004). Pp.290-305. London and NewYork: Routledge.

[7] Diaz Cintas, J. (2009). New Trends in Audiovisual Translation. (Ed.). CromWell Press: UK.

[8] Diaz Cintas, J. and Anderman, G. (2009). (Eds.). Audiovisual Translation: Language Transfer on Screen. UK: Palgrave Macmillan.

[9] Gambier, Y. (2003) Screen transadaptation: perception and reception. The Translator Vol.9, No.2, pp. 171-189.

[10] Georgakopoulou, P. (2009). Subtitling for the DVD Industry. In J. Diaz Cintas and G. Anderman (Ed.). Audiovisual Translation: Language Transfer on Screen. Pp. 21-35. UK: Palgrave Macmillan.

[11] Gottlieb, H. (1994). Subtitling: a New University Discipline. In Teaching Translation and Interpreting. Pp. $290-295$. Amsterdam: John Benjamins.

[12] Gottlieb, H. (1998). Subtitling. In M. Baker. (Ed.). Routledge encyclopedia of translation studies. pp. 244-248. London and New York: Routledge.

[13] Gouadec, D. (2007). Translation as a profession. Amsterdam/Philadelphia: John Benjamins Publishing. 
[14] Hatim, B. \& Mason, I. (1997). The Translator as Communicator. London and New York: Roultedge.

[15] Hatim, B. \& Munday, J. (2004). Translation: An advanced resource book. London: Routledge.

[16] Jabbarzadeh, F. (2007). Subtitling Norms: a Comparative study of Iranian and American Film. Translation Studies, vol.5, No.19, pp. 9-30.

[17] Klaudy, K. (1998). Explicitation. In M. Baker(Ed.). Routledge encyclopedia of translation studies. (1998). pp. 80-84. London and New York: Routledge.

[18] Perego, E. (2003a). Evidence of explicitation in subtitling: Towards a categorisation. Across Languages and Cultures 4 (1), $63-$ 88.

[19] Pettit, Z. (2004). The Audio-Visual Text: Subtitling and Dubbing Different Genre. Meta: Translators' Journal, vol. 49(1). pp. 25-38.

[20] Pym, Anthony. (2005). Explaining Explicitation. In New Trends in Translation Studies. In Honour of Kinga Klaudy. Krisztina Károly(Ed.). Budapest

[21] Roozgar, M.B. (2007). Textual Explicitation in two Text-types: Expressive and Informative. Translation Studies, vol. 5, No.19, pp. 31-48.

[22] Sanchez, D. (2004). Subtitling methods and Team-Translation. In P. Orero (Ed.). Topics in Audiovisual Translation (2004). Pp. 15-20. Amsterdam: John Benjamins.

[23] Séguinot, C. (1988). Pragmatics and the Explicitation Hypothesis. In erudite: TTR: traduction, terminologie, rédaction, vol. 1 , No. 2, pp. 106-113.

Masumeh Yazdani Moghaddam, PHD student in language teaching at Chabahar Marin University, Iran, 1986, she got MA in English translation studies in Feb. 2012. Her main interests are English translation and linguistics.

Sommayeh Shahraki Deh Sukhteh got MA in statics. She is instructor in Zabel University, Iran. Interdisciplinary subjects and statistics are her main topics of interest.

Mansureh Delarami Far, PHD student of linguistics.1995. She is instructor in Zabol and Zahedan University, Iran. Her main interests are linguistics and interdisciplinary subjects. 